(CC BY 4.0) | ISSN 2525-3409 | DOI: http://dx.doi.org/10.33448/rsd-v9i9.6531

\title{
Estudo em casa na pandemia: panorama interdisciplinar sobre os responsáveis e filhos
} Home study in pandemic: interdisciplinary overview of parents and children

Estudio en el hogar en pandemia: panorama interdisciplinario de padres e hijos

Recebido: 09/07/2020 | Revisado: 15/07/2020 | Aceito: 31/07/2020 | Publicado: 10/08/2020

\section{Célia Regina da Silva Rocha}

ORCID: http://orcid.org/0000-0002-9864-7253

Universidade Cruzeiro do Sul, Brasil

E-mail: crsrocha@gmail.com

Juliano Schimiguel

ORCID: http://orcid.org/0000-0001-8552-7984

Universidade Cruzeiro do Sul, Brasil

E-mail: schimiguel@gmail.com

Graziela Viana Pires

ORCID:http://orcid.org/0000-0002-3829-3350

Universidade Cruzeiro do Sul, Brasil

E-mail: graziela.vianapm@gmail.com

\section{Resumo}

Este artigo foca em uma investigação sobre o panorama interdisciplinar na relação entre responsáveis e filhos durante as atividades e estudos escolares em suas casas, neste momento de pandemia e confinamento. Estudo exploratório e descritivo, o instrumento utilizado para a coleta de dados do tipo survey foi feito através do Google Forms, para levantar as percepções e características dessa interação entre pais e filhos, neste momento em meio a pandemia do COVID-19. Participaram 66 graduandas de diferentes áreas do conhecimento. Os resultados indicaram que os responsáveis pelas crianças afirmaram que estas são colaborativas, desenvolvem suas atividades de trabalho e estudo em ambiente conjunto, consideram que tem preparo pedagógico para auxiliar na execução das atividades escolares dos filhos. Utilizam os equipamentos PC, Notebook e Smartphone para desenvolver as atividades de estudo e trabalho, a maioria com internet banda larga.

Palavras-chave: Pandemia do COVID 19; Relação pais-filhos; Tecnologia da Informação e Comunicação. 


\section{Summary}

This article focuses on an investigation on the interdisciplinary panorama in the relationship between parents and children during school activities and studies in their homes, at this time of pandemic and confinement. An exploratory and descriptive study, the instrument used for collecting survey data was made through Google Forms, to raise the perceptions and characteristics of this interaction between parents and children, at this moment in the midst of the COVID-19 pandemic. 66 undergraduate students from different areas of knowledge participated. The results indicated that those responsible for the children stated that they are collaborative, develop their work and study activities in a joint environment, consider that they have pedagogical training to assist in the execution of their children's school activities. They use PC, Notebook and Smartphone equipment to develop study and work activities, most with broadband internet.

Keywords: COVID pandemic 19; Parent-child relationship; Information and communication technology.

\section{Resumen}

Este artículo se centra en una investigación sobre el panorama interdisciplinario en la relación entre padres e hijos durante las actividades escolares y los estudios en sus hogares, en este momento de pandemia y confinamiento. Un estudio exploratorio y descriptivo, el instrumento utilizado para recopilar datos de encuestas se realizó a través de Formularios de Google, para elevar las percepciones y características de esta interacción entre padres e hijos, en este momento en medio de la pandemia de COVID-19. Participaron 66 estudiantes universitarios de diferentes áreas del conocimiento. Los resultados indicaron que los responsables de los niños declararon que son colaborativos, desarrollan su trabajo y estudian actividades en un ambiente conjunto, consideran que tienen capacitación pedagógica para ayudar en la ejecución de las actividades escolares de sus hijos. Utilizan equipos de PC, portátiles y teléfonos inteligentes para realizar actividades de estudio y trabajo, la mayoría de ellos con Internet de banda ancha.

Palabras clave: Pandemia COVID 19; Relación padre-hijo; Tecnología de la información y la comunicación. 


\section{Introdução}

Durante o confinamento devido à pandemia de COVID-19, as pessoas têm recorrido ao uso das Tecnologias de Informação e Comunicação (TICs) para poder viabilizar o trabalho, os estudos, bem como a interação social com seus familiares, amigos, colegas de faculdade, e parceiros de empresa.

De acordo com Aquino Filho et al. (2015), a evolução das tecnologias de informação e comunicação (TICs), provocaram grandes transformações e abriram o leque de possibilidades para se trabalhar com o ensino-aprendizagem, assim como, para atuar com diferentes segmentos e ramos de atuação da sociedade como um todo. Para os autores, as mídias digitais podem e devem ser utilizadas no âmbito pedagógico nas escolas, fomentando a motivação, espirito empreendedor e crítico perante as atividades propostas em sala de aula.

Especificamente essas salas de aula notadamente são as salas de aula presenciais, ou ainda os espaços virtuais de ensino-aprendizagem, que é exatamente o foco deste artigo. Os ambientes virtuais de ensino-aprendizagem (AVAs), de acordo com Vilaça et al. (2015), são desenvolvidos por instituições acadêmicas ou privadas, com o intuito de fornecer para os alunos ferramentas para serem utilizadas durante o andamento das aulas / disciplinas / cursos, com foco na facilitação do compartilhamento de materiais de estudo, disponibilizar fóruns de discussão, gerenciar o recebimento de atividades e tarefas dos alunos, promover a interação entre professores e alunos como através de chat, web conferência, entre outros. São sistemas que promovem o melhor aproveitamento do ensino-aprendizagem nas modalidades presencial, semipresencial ou mesmo EaD - Ensino a Distância.

Entre alguns exemplos de ambientes virtuais, pode-se destacar o Blackboard, Moodle, Dokeos, Edmodo, Canvas, Google Sala de Aula, entre outros. Em grande parte, esses AVAs oferecem ferramentas para interação entre professor e alunos, a saber: fóruns de discussão, chat (bate papo), e no âmbito da pandemia de covid-19 com respectivo confinamento das famílias, o uso intenso de ferramentas de vídeo ou web conferência, com interação via texto, imagem e áudio, em tempo real e ao vivo.

Muitos pais e suas famílias estão trabalhando em suas casas na modalidade homeoffice, sendo necessário, em muitos casos, cumprir o horário pré-estabelecido de oito horas diárias, visto que os computadores através dos softwares, muitas vezes, monitoram até mesmo com webcam o trabalho e presença ao longo do dia. Alguns desses pais, ou seus filhos, estão também frequentando cursos superiores (ou ensino fundamental, médio, técnico) na 
modalidade de ensino remoto (ao vivo), usando ferramentas colaborativas como Zoom Meeting, Skype, Blackboard Collaborate, Google GMeet, Whatsapp, Webex Meetings Cisco.

Aliado a isso, algumas pessoas dentro de suas famílias mudaram o horário de trabalho nos moldes do home-office; fazendo com que a família precise fazer todo um planejamento para realizar todas as atividades do dia: trabalho, estudos, tarefas de casa, compras no supermercado (agora é imprescindível lavar os produtos com certa atenção), entre outros. Ainda, nesse contexto, vários dispositivos estão sendo necessários em casa, como um ou mais notebooks, smartphones, tablets, etc.

Entretanto, essa não é exatamente a realidade de grande parte das famílias brasileiras. Muitos estudantes estão frequentando seus cursos através do smartphone, com internet $3 \mathrm{G}$ ou 4G, limitada. Ainda, muitos desses alunos não conseguem assistir as aulas em tempo real, necessitando deixar para assistir posteriormente, perdendo muitas vezes o momento de interação entre docente e alunos na sala de aula virtual.

Compreende-se que mudanças profundas no cotidiano da população brasileira ocorreram em função da quarentena, adotada para o enfrentamento da pandemia da COVID19. Este estudo teve por objetivo de investigar as relações entre os responsáveis e os filhos que estão em confinamento em casa, realizando tarefas do trabalho e escolares em conjunto, muitas vezes no mesmo ambiente.

Este artigo está organizado da seguinte maneira: primeiramente a introdução ao tema, em seguida discorre-se sobre o referencial teórico; na sequencia define-se o método de pesquisa, logo após são expostos os resultados da aplicação de um questionário na plataforma Google docs. com os pais de alunos; e por fim conclui-se o trabalho.

\section{Dificuldades para Conciliar Estudo, Trabalho e a Relação entre Mães e Filhos}

A sociedade, no atual cenário, vem sofrendo mudanças significativas, o tempo livre está cada vez mais escasso, atrelado às inúmeras atribuições, aumento no nível de exigência e demandas sociais, de trabalho e de estudo, maior tempo gasto com a utilização dos recursos tecnológicos. No mundo globalizado, o avanço de novas e complexas tecnologias propiciando a aceleração ao acesso às informações, consequentemente exigindo novas formas de pensar e agir (Crepaldi, 2017). Estas mudanças vividas por nossa sociedade causam impactos nas interações familiares e qualidade de vida das pessoas, com estas mudanças na sociedade contemporânea, os papéis dentro do âmbito familiar, também sofreram mudanças, em algumas famílias as mães ainda permanecem como as únicas a cuidarem do bem-estar das 
crianças, em outras famílias, a mãe não exerce mais os cuidados dos filhos, ficando estes aos cuidados de familiares ou de terceiros. Também surgiram novos modelos familiares oriundos destas mudanças, provocando alterações significativas nas relações familiares, como por exemplo, os homens deixaram de ser os únicos provedores da casa, papel que passou a ser assumido pelas mulheres, que conquistaram sua independência, se inserindo no mercado de trabalho e assumindo postos mais elevados, e optando pela por postergar o casamento ou mesmo permanecer solteira (Dessen e Polonia, 2007). Segundo Nogueira (2006), com o surgimento dos novos tipos de famílias, ocorre a diminuição do número de casamentos com aumento da idade tanto para o casamento como consequentemente para a procriação. Assim as mulheres mais independentes e autônomas passaram a fazer escolhas, dentre elas fazer parte do contingente de estudantes universitários.

A entrada na universidade, geralmente é caracterizada por processos complexos de transição e adaptação, conflitos relacionados as novas questões pessoais, envolvimento com a vida pessoal, aprendizado e desempenho acadêmico. A Universidade também se configura como um meio para desenvolver habilidades interpessoais, ideológicas, atitudes e comportamentos (Pinho et al, 2015), tomada de responsabilidade do processo de aprendizagem, atividades extraclasse e extracurriculares. O aumento do nível de escolaridade também pode significar a melhora nas condições de acesso e inserção no mercado de trabalho e, consequentemente, da condição social e econômica. Almeida e Soares (2003), afirmam que a adaptação e o sucesso acadêmicos não se evidenciam exclusivamente nos aspectos curriculares, mas envolvem identidade, relações interpessoais mais maduras com os pares, os professores e a família. Neste trabalho vamos enfocar as atividades desenvolvidas pelos alunos, as prioridades estabelecidas, a ressignificação do lugar das atividades acadêmicas em sua vida enquanto estudante universitário e/ou na condição de pais auxiliando os filhos.

As transformações vividas na atualidade provocaram mudanças na forma de lidar e interagir com as crianças, que possuem uma natureza própria e singular, onde revelam seu esforço em compreender o mundo em que vivem, Meira (2003) afirma que a criança na sociedade contemporânea é afetada pelo meio no qual está inserida. $\mathrm{Na}$ família, as preocupações principais são outras, entre elas o processo de socialização da criança, neste ambiente a criança tem seu primeiro contato social, que funciona como intercessor dos padrões, modelos e influencias culturais presentes em nossa sociedade (Dessen e Polona,2007). A família é a primeira mediadora entre o homem e a cultura, encarregada de transmitir o conhecimento, constitui-se na unidade dinâmica das relações afetivas, social e cognitiva (Dessen e Polonia,2007, p.22). Assim, a criança é diretamente influenciada pelos 
familiares, a partir deste primeiro contato social, a criança revela seu esforço de compreender o mundo que a cerca, as relações estabelecidas, inclusive aquelas relações contraditórias presenciadas no ambiente familiar. influenciada pelos familiares, a partir deste primeiro contato social, a criança revela seu esforço de compreender o mundo que a cerca, as relações estabelecidas, inclusive aquelas relações contraditórias presenciadas no ambiente familiar. outro aspecto refere-se a diferença entre as gerações e, sobre uso excessivo e abusivo de celulares e a jogos digitais violentos tão presentes na atualidade (silva et al., 2020). apesar disso a criança tem uma natureza própria e singular na sua forma de pensar e de agir, que as caracteriza como seres que pensam o mundo de um modo próprio. Cabe a família prover à criança amor, carinho e atenção no sentido de atender a essas necessidades (Silva et al, 2020).

Apesar disso a criança tem uma natureza própria e singular na sua forma de pensar e de agir, que as caracteriza como seres que pensam o mundo de um modo próprio.

Este estudo foi realizado junto aos graduandos de uma universidade privada da cidade de São Paulo. São jovens e adultos em sua maioria trabalhadores, que estudam pela manhã e trabalham nos períodos da tarde e noite ou trabalham durante o dia e estudam no período noturno. Como mencionamos anteriormente, a mãe não é mais a única a cuidar dos filhos, que ficam aos cuidados de terceiros (creches e maternais) ou quando o pai está em casa, as crianças ficam sob seus cuidados. No entanto, a maioria permanece sob os cuidados da mãe, numa jornada tripla, que envolve o trabalho dentro e fora de casa e seu momento de estudo, não apenas seu, enquanto estudante universitária, mas também acompanhando as atividades escolares de seus filhos. Porém, no cenário atual, com tantas mudanças e transformações nas relações e papéis familiares, os casais sobrecarregados e envoltos com as questões do trabalho, com níveis de exigência cada vez mais elevados, além de outras atividades extras para realizar, restando muito pouco tempo para se dedicarem aos filhos, principalmente no que diz respeito a participação na vida e tarefas escolares do filho (Almeida,2014). Neste sentido, Nogueira afirma que "os pais se tornam assim, os responsáveis pelos êxitos e fracassos escolares e profissionais dos filhos (2006, p.162). Soares, Souza e Marinho (2004) referem a importância do envolvimento dos pais na vida acadêmica dos filhos, segundo os autores, este envolvimento propicia condições favoráveis à aprendizagem.

Para a criança a família é além de ser um espaço favorecedor para o desenvolvimento afetivo-emocional e social da a criança, mas também se configura um espaço de aprendizagem, para Vigotsky (1998) o aprendizado se inicia muito antes da entrada da criança na escola, mediada pelos pais, irmãos e demais familiares que vivem junto a criança. Grolnick e Stowiaczke (1994) e Marturano (1999) referem os efeitos positivos do envolvimento dos 
pais, nas atividades escolares, ao encorajamento verbal e de reforço direto de comportamentos que resultam na melhora do desempenho acadêmico e desenvolvimento educacional da criança, o que segundo Ferhamann, Keith e Reimers (1987) implica no suporte e monitoramento diário das atividades e do progresso escolar.

Este é um fator que tem gerado estresse, pois este é um fator que interfere e compromete os estudos, tanto dos pais quanto dos filhos. Outro fator gerador de estresse diz respeito ao acompanhamento das tarefas escolares dos filhos, os conflitos surgem quando os pais se queixam que os filhos trazem muitas tarefas para serem feitas em casa e que eles não têm tempo suficiente para auxiliar os filhos, além da dificuldade para estabelecer uma rotina de horários para o estudo e realização das atividades enviadas pela escola. Mas como dar conta destas atividades em tempos de pandemia? Uma vez que o trabalho agora está sendo realizado em Home office, tendo que conciliar o uso do computador, com as atividades escolares dos filhos, as suas próprias atividades acadêmicas, quase que invariavelmente nos mesmos horários.

\subsection{Recursos tecnológicos que auxiliam no processo de aprendizagem}

Hodges et al. (2020) discutiram em seu trabalho as diferenças entre o Ensino Remoto Emergencial (ERT) e o Ensino Online Tradicional. Para os autores, experiências de aprendizado online bem planejadas são significativamente diferenciadas de cursos oferecidos de maneira tradicionalmente online, em resposta a crises ou desastres, com é o caso da crise de pandemia / COVID-19 que se vivencia atualmente. Ainda segundo os autores, várias escolas e universidades têm trabalhado massiva e ativamente para manter as aulas durante a pandemia de COVID-19. Neste cenário, as instituições de ensino tiveram que tomar decisões efetivas e rápidas, pois trata-se de um problema de emergência de saúde pública. Muitas escolas optaram por cancelar o contato face-a-face de sala de aula, incluindo atividades e aulas de laboratórios, bem como, outras experiências de aprendizado.

Algumas instituições de ensino fizeram a migração para o modelo remoto quase que automaticamente, pois já tinham uma vivência, experiência e infraestrutura em cursos à distância $(\mathrm{EaD})$. Outras instituições buscaram num primeiro momento um modelo híbrido, disponibilizando atividades para os alunos enviadas via e-mail, ou mesmo utilizando vídeos já disponíveis em plataformas e redes sociais como o Youtube, ou GNoogle sala de aula. Podese também destacar, aquelas escolas que adiantaram as férias dos alunos com dois motivos: primeiro na expectativa que em um mês o problema da pandemia seria resolvido, e segundo 
para poder fomentar a formação de professores, bem como, para melhor preparo de sua equipe pedagógica, equipe de infraestrutura tecnológica, departamento de tecnologia da informação, entre outros.

Para Teixeira e Finardi (2013), existe uma convicção que há a necessidade de se institucionalizar processos de formação continuada de professores, em todas as instâncias educacionais, de forma a promover conhecimentos técnicos em tecnologias de informação e comunicação, conhecimentos pedagógicos, bem como, aprofundar o debate, discussão e reflexão sobre a melhor apropriação das TICs em contextos educacionais reais. Ainda, para os autores, a formação continuada é essencial na utilização das TICs no ensino presencial, por possibilitar a incorporação de novas metodologias de ensino e ressignificações do papel docente bem como discente em contextos de ensino-aprendizagem.

Acrescenta-se às falas de Teixeira e Finardi (2013), que a formação também é essencial para a implementação do ensino semipresencial, do totalmente a distância (EaD) educação a distância tradicional, e até mesmo para o ensino remoto emergencial, destacado pelo professor Hodges. Ainda no trabalho dos autores (op.cit.), foi utilizada a conferência web em um estudo de caso com uma turma de um curso de extensão intitulado 'Formação Continuada para a Utilização das TICs no Ensino Presencial da UFES'. O curso teve como foco: produzir e publicar conteúdos utilizando tecnologias digitais; além de incentivar a inserção de práticas de ensino-aprendizagem em plataformas virtuais de aprendizagem.

Devido ao confinamento, grande parte do trabalho de formação continuada de professores precisou ser feito também de maneira remota, através de cursos online, organizados pela equipe pedagógica da própria instituição de ensino, usando as ferramentas de videoconferência que posteriormente os mesmos professores iriam utilizar com seus alunos.

Pode-se também destacar os inúmeros seminários e webinars organizados pelas escolas, com o intuito de promover o diálogo e discussão sobre tópicos e ferramentas tecnológicas a serem utilizados pelos professores, para tornar as aulas mais lúdicas. Neste âmbito, pode-se citar algumas ferramentas como: Kahoot, Socrative, Enquetes, Formulários para realização de testes virtuais, entre outros.

\section{Metodologia}

Estudo exploratório e descritivo, sendo que os dados apresentados foram coletados com a utilização da ferramenta Google Forms, questionário com nove perguntas, com o 
objetivo de investigar as relações entre os responsáveis e os filhos que estão em confinamento em casa, realizando tarefas do trabalho e escolares em conjunto, muitas vezes no mesmo ambiente. A amostra composta de 66 participantes do sexo feminino e masculino, a coleta de dados foi realizada no período compreendido entre os dias 5 de maio de 2020 a 3 de junho de 2020.

A coleta de dados foi realizada nos moldes do método survey. A pesquisa survey pode ser configurada como a obtenção de dados sobre características e opiniões de um grupo / amostra a ser investigado. Esse grupo representa a população como um todo, e realiza-se o levantamento de dados através de um instrumento específico, geralmente um questionário. $\mathrm{O}$ questionário desta pesquisa foi projetado encima da plataforma Google Forms, Google Docs e Google Drive.

O método survey têm como características produzir descrições quantitativas de uma determinada população; e fazer a utilização de um instrumento de coleta de dados predefinido; neste caso, foi usado o questionário (Freitas et al., 2000).

O survey deve ser utilizado quando (i) se deseja responder questões do tipo “o que?", “por que?", “como?”, ou seja, quando o foco de interesse é sobre "o que está acontecendo"; (ii) não se tem interesse em controlar variáveis dependentes e independentes; (iii) o ambiente natural é a forma mais adequada para se estudar o fenômeno em análise; (iv) o objeto em foco ocorre atualmente ou num passado não muito distante.

O método survey pode ainda ter sua classificação quanto ao seu propósito: explanatória, exploratória e descritiva. A pesquisa explanatória tem como meta testar uma teoria e as suas relações causais. A pesquisa exploratória foca na familiarização com os itens tratados ou na sua identificação, com ênfase nos conceitos a serem medidos, objetivando novas descobertas e suas dimensões dentro da população de interesse. A pesquisa descritiva busca identificar quais opiniões são manifestadas dentro de uma população; descrevendo sua distribuição e fazendo comparações.

Souza et al. (2019), realizaram uma pesquisa do tipo survey / levantamento de insetos aquáticos em um trecho do Rio Tijuca, na Floresta da Tijuca, no Rio de Janeiro / RJ. Foram coletadas doze amostras, em três habitats diferentes, e dois mesohabitats distintos.

Nos trabalhos de Roque et al. (2020), foi realizada uma pesquisa de campo com o objetivo de abordar a importância da alimentação saudável com crianças das séries iniciais de uma escola da rede pública do município de Dois Vizinhos, no Estado do Paraná. A atividade foi efetivada com a aplicação de um questionário buscando analisar o conhecimento prévio dos estudantes e, depois, proferindo uma palestra sobre o tema 'alimentação'. Foram também 
exibidos vídeos educativos e atividades lúdicas para promover a percepção sobre a importância de se consumir alimentos nutritivos para uma boa qualidade de vida.

\section{Dinâmica das Atividades Realizadas}

De acordo com os dados obtidos na pesquisa, Gráfico 1 - que se refere a colaboração do filho no desenvolvimento das atividades escolares em casa, a maior parte dos participantes demonstrou que seus filhos colaboram $53,03 \%(n=35)$, ou colaboram parcialmente $37,88 \%$ $(n=25)$, apenas $9,09 \%(n=6)$ dos participantes responderam que não tem cooperação.

Gráfico 1. Colaboração frente as atividades desenvolvidas.

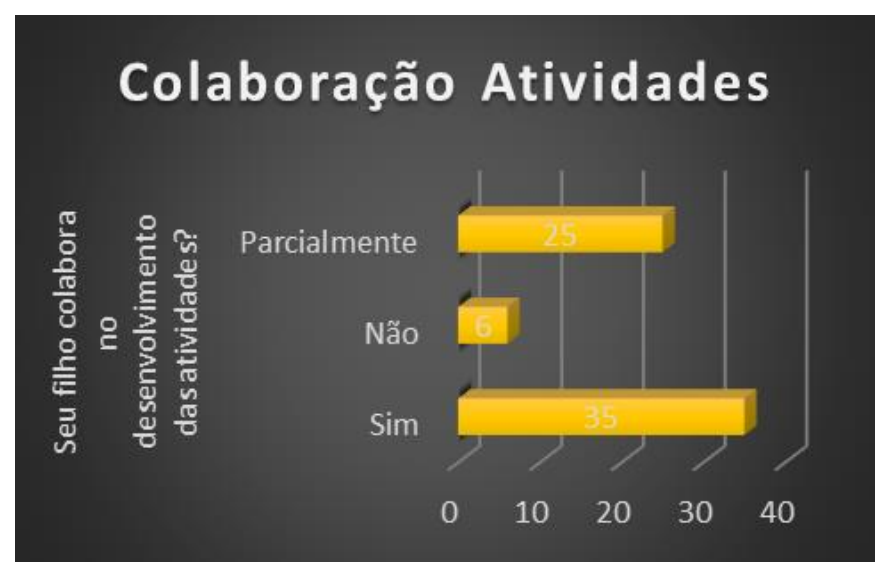

Fonte: Autores.

Em relação ao ambiente adotado para o momento de estudos e execução de atividades como o home-office (trabalho remoto em casa), Gráfico 2 - 51,52\% (n=34) informaram que fazem as atividades em ambiente conjunto. De modo contrário, 48,48\% (n=32), responderam que utilizam ambientes separados para a execução das tarefas.

Gráfico 2. Ambiente adotado para a realização das atividades.

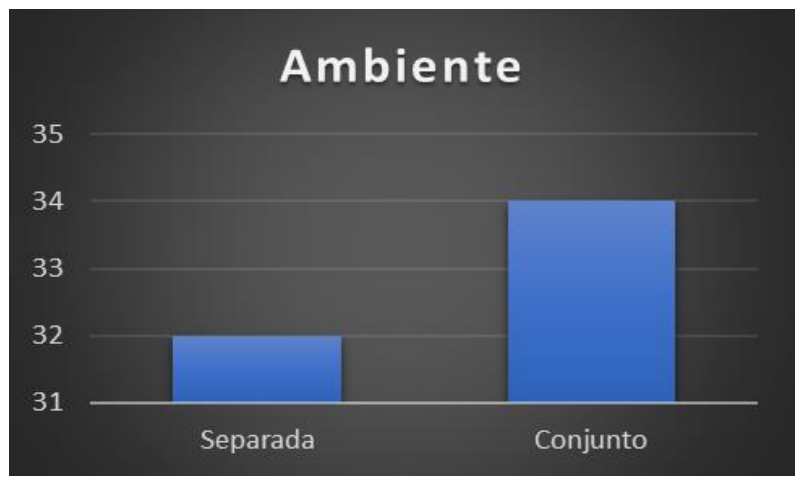

Fonte: Autores. 
Na Gráfico 3 - se refere ao preparo pedagógico para executar as aulas com os filhos, os participantes preponderantemente se avaliaram como tendo preparo parcial $56,06 \%(\mathrm{n}=37)$, $27,27 \%(\mathrm{n}=18)$, responderam que se consideram completamente preparados para auxiliar, e $16,67 \%(n=11)$, disseram que não possuem preparo para auxiliar os filhos nas aulas.

Gráfico 3. Preparo pedagógico dos pais para auxiliar os filhos na realização das atividades escolares.

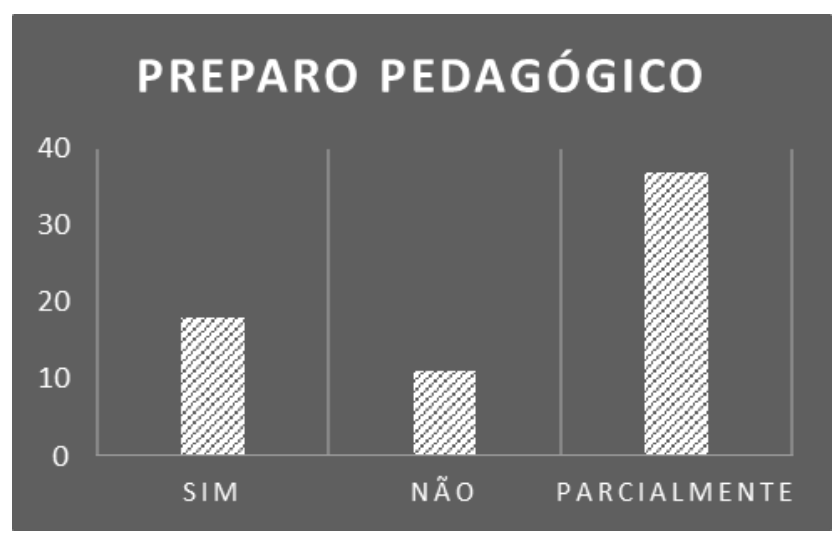

Fonte: Autores.

Na Gráfico 4 - observa-se os dados relativos a necessidade de desenvolver outras atividades, além do auxílio aos filhos, 40,91\% ( $\mathrm{n}=27)$ relataram que também estudam, $27,27 \%(\mathrm{n}=18)$ informaram que realizam o trabalho remoto home-office, $16,67 \%(\mathrm{n}=11)$ informam que não realizam nenhuma outra atividade, enquanto $15,15 \%(n=10)$, responderam que estudam e trabalham além de auxiliar o filho a realizar suas atividades.

Gráfico 4. Realização de outras atividades: home-office e estudo.

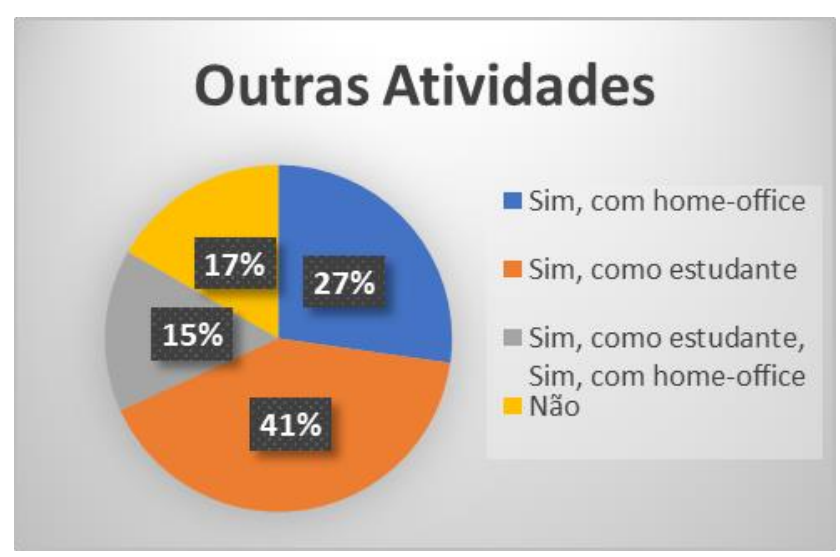

Fonte: Autores. 
Na Gráfico 5 - que concerne ao uso do ambiente virtual/digital, 93,93\% ( $\mathrm{n}=62)$ dos participantes responderam que fazem uso deste ambiente. Ao contrário, 6,06\% ( $\mathrm{n}=4)$, disseram que não fazem uso do ambiente virtual/digital.

Gráfico 5. Uso de ambiente virtual/digital.

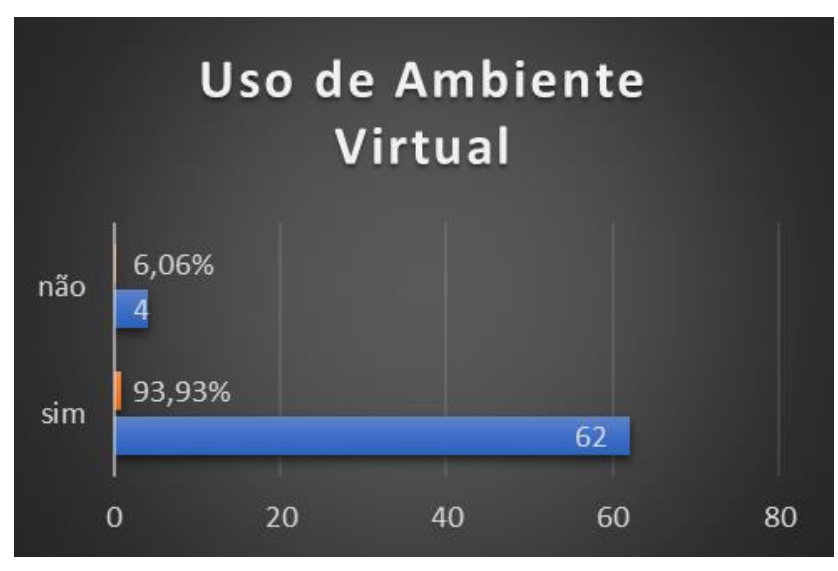

Fonte: Autores.

Na Gráfico 6 - demonstra as informações quanto ao uso para trabalho e estudo, 93,93\% ( $\mathrm{n}=62$ ) informaram que utilizam computador pessoal (PC) de mesa, notebook ou smartphone, diferente de 6,06\% $(n=4)$ que relataram utilizar estes meios em casa de parentes e amigos, pois não possuem tais equipamentos em suas casas.

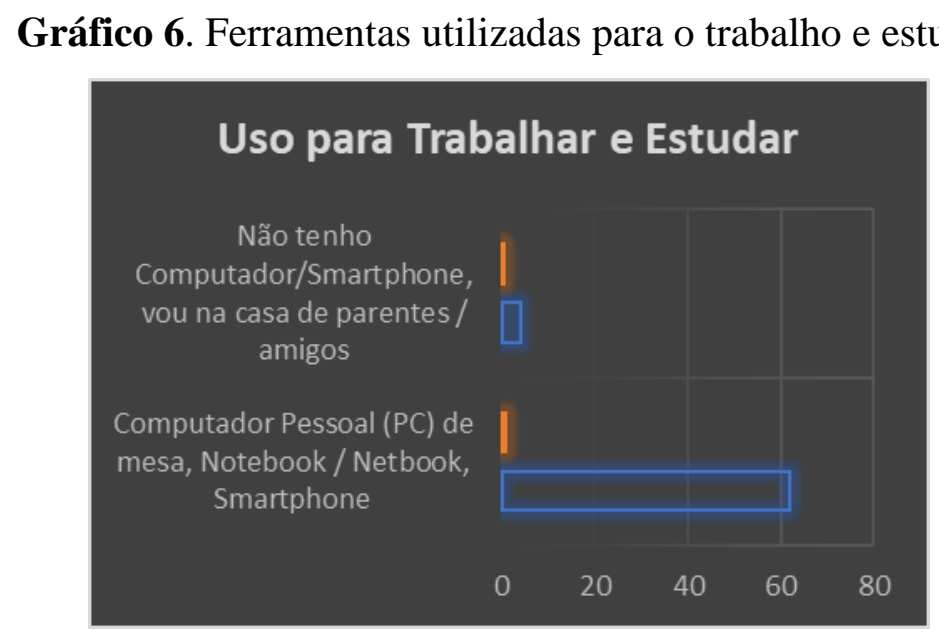

Fonte: Autores.

Relativo ao tipo de internet, utilizada em casa - Gráfico 7, 65,15\% (n=43) informam que tem banda larga, sendo que 19,69\% $(n=13)$ relatam usar a internet do smartphone $(3 \mathrm{G}$, $4 \mathrm{G}, 5 \mathrm{G}) .15,15 \%(\mathrm{n}=10)$ marcaram que fazem uso de internet compartilhada (wifi do vizinho, etc.). 
Gráfico 7. Tipo de internet utilizada.

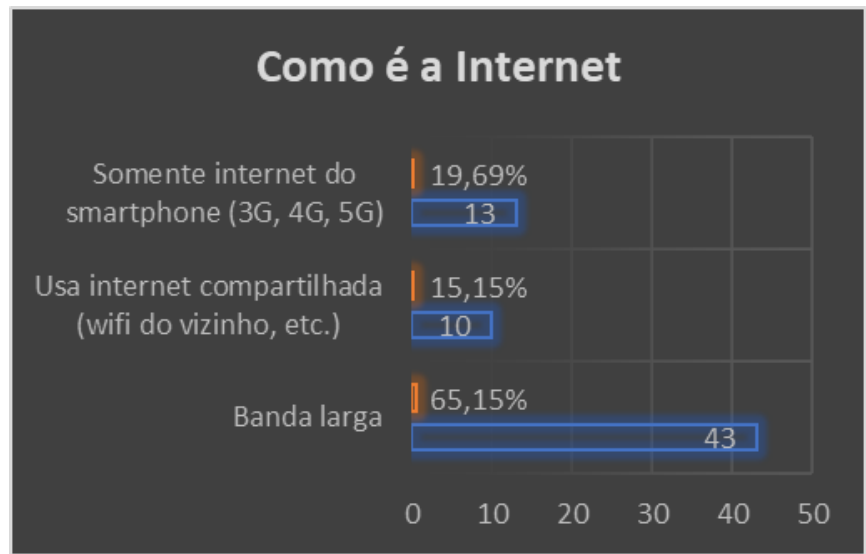

Fonte: Autores.

\subsection{Discussão}

O cenário atual correspondente a uma pandemia pelo novo corona vírus (COVID-19), não se resume puramente a um processo biomédico, porquanto, foi necessária a adoção de medidas como distanciamento social e quarentena, que por sua vez intensificaram as relações familiares, estas, antes distribuídas cotidianamente a outros convívios. Tais relações podem ser entendidas como contraditórias também, no sentido de que atualmente não há fronteiras e nem limites para os contatos com praticamente todo o mundo, facilitado pelas tecnologias de informação e comunicação (TICs), por outro lado, as vivencias estão restritas as fronteiras físicas das casas, crianças presas em espaços pequenos e superprotegidos, assistindo televisão, jogando vídeo game ou utilizando outros recursos tecnológicos disponíveis.

Neste contexto dinâmico de mudanças e incertezas emergem preocupações de natureza diversa que afetam o estado emocional, tanto de pais, quanto de filhos. De acordo com (Ornell et al., 2020), conforme citado por (Schmidt et al., 2020, p. 03), a preocupação com a saúde mental costuma ser negligenciada, pois a saúde física dos indivíduos tende a ter maior atenção dos profissionais e gestores de saúde, em função ao combate do agente patogênico, sendo que as implicações da saúde mental, quando subestimadas, podem ser mais duradouras. A preposição anterior pode ser ilustrada com contribuições de comentários adicionais de alguns participantes da pesquisa, que relatam "ser impossível não se estressar neste momento", "as casas são pequenas é difícil um ambiente somente para estudo", "me esforço para fazer em dia, mas é muito difícil conciliar" e "socorro". Além disso, a amostra demonstrou que mais da 
metade dos responsáveis realizam outras tarefas, como o home-office, somado ao auxílio ao filho e ao seu próprio estudo, evidenciando-se assim a sobrecarga.

Se por um lado os pais, mães e responsáveis se mostraram angustiados pelas novas demandas e adaptações de seus trabalhos, preocupações frente a nova rotina da casa, divisão de espaços e tarefas, refeições e, principalmente, a dificuldade em saber lidar com todos os aspectos mencionados anteriormente. Por outro lado - numa visão mais otimista, estes pais e responsáveis puderam perceber este momento como oportunidade de redescobrir e aprofundar o relacionamento com o filho, pois teoricamente agora tem mais disponibilidade para aproveitarem esse tempo juntos com qualidade.

Em relação aos filhos, sendo crianças ou jovens, estes tem deixado de ocupar os espaços públicos, a escola, casa de amigos, avós e passam tanto quanto seus cuidadores por estresses, medos, inseguranças dentre outras emoções, das mais primitivas as mais sofisticadas, cada qual em sua fase do desenvolvimento.

No tocante as relações entre mães e filhos pequenos, o pediatra e psicanalista Winnicott (1958/2000), discorre sobre o desenvolvimento emocional saudável, mas para isso, o bebê deve ser acolhido por um ambiente estável e por uma mãe - ou alguém que faça esse papel - que reconheça as necessidades, e as ofereça na medida certa para o bebê. O autor (op. cit.), utiliza termos fundamentais como a "preocupação materna primária", "ambiente facilitador" e "mãe suficientemente boa" significando estes, a importância de desenvolver a adaptação do meio ambiente as necessidades do bebê, além de propiciar sustentação holding e fazer o manuseio handling adequadamente (BELO, 2013, p. 99). Quando estas tarefas são desenvolvidas com sucesso, ou poucas falhas, estes caminham para maturidade e responsabilidade quando adultos.

Já em relação aos adolescentes, entende-se que estes atravessam transformações físicas relacionadas a puberdade, emocionais pelo luto simbólico da perda do corpo infantil e dos pais da infância, além das sociais conexa com escolha de profissão, quando não, em estratos sociais menos favorecidos já precisam trabalhar para auxílio na renda familiar. Paralelamente, compreende-se que neste período a rede emocional está mais ativa, toda via, a rede de controle cognitivo que regula as respostas aos estímulos, ocorre seu amadurecimento gradual até a idade adulta (Papalia; Feldman, 2013).

Sabe-se que os processos educativos de ensino e aprendizagem são um constante desafio para educadores e professores, estes que foram formados e constantemente se aperfeiçoam para levar conhecimento a alunos do ensino fundamental ao superior. $\mathrm{O}$ panorama atual, levou pais, mães e responsáveis a assumirem o papel antes conferido 
majoritariamente as instituições de ensino, que anterior, ao período da pandemia, este envolvimento abrangia idas à escola e a participação nas reuniões promovidas pela escola.

A escola por sua vez, objetiva o desenvolvimento escolar da criança, incentiva o envolvimento dos pais na vida escolar do filho de forma mais efetiva (Soares, Souza e Marinho, 2004), no entanto, durante este período de pandemia, o estresse por parte dos pais permanece e está relacionado ao acompanhamento constante na execução das tarefas solicitadas pela escola/professores. Dentre elas pode-se mencionar as mudanças na prática de ensino, que agora acontecem de modo remoto, além de ter que desempenhar suas atividades de trabalho ou de suas próprias atividades acadêmicas. Ainda assim, percebe-se um dado positivo em relação a percepção dos participantes da pesquisa, sobre o sentirem-se preparados pedagogicamente para auxiliar seus filhos, a maior parte da amostra 83,33\%, informou sentirse parcial ou completamente preparados para executar tal tarefa. Contrário aos resultados obtidos no estudo realizado por Soares, Souza e Marinho (2004), que afirmaram aspectos que dificultaram a participação efetiva dos pais nas atividades escolares dos filhos fosse positiva, tais como desconhecimento dos assuntos estudados pelos filhos e a falta de tempo.

Os participantes deste estudo, também apontaram como aspecto favorável a quantidade elevada de colaboração ou colaboração parcial na realização das tarefas, 90,91\%, mesmo tendo sinalizado que possuíam apenas um equipamento, tendo que compartilhá-lo com o filho ou para desenvolver as atividades home-office e estudo. Existe um esforço por parte dos pais para conseguir viabilizar as aulas de seus filhos no modelo remoto, isso porque eles também estão trabalhando em home-office, inclusive em decorrência da pandemia, muitos desses pais mudaram seu horário de trabalho, buscando conciliar seus horários de estudo, ensino superior e/ou médio/técnico, em horários específicos ao longo do dia.

No tocante a aprendizagem, foram utilizadas as contribuições relevantes de Vygotsky (1998), suas ideias centrais estão pautadas no entendimento biopsicossocial, sendo que as funções psicológicas tem suporte biológico consistindo em produto de atividade cerebral, o funcionamento psicológico é regido pelas relações sociais entre o indivíduo e o meio externo, e o social é mediado por sistemas simbólicos que é o processo de intervir na relação tornando possível a aproximação. A aprendizagem pode ocorrer de diversas formas, através de jogos, brincadeiras, instruções formais ou do trabalho realizado entre um aprendiz e outro com mais experiência, acontecendo fundamentalmente pela mediação.

A Zona de Desenvolvimento Proximal - ZDP respalda-se na distância mediada pelo nível atual do desenvolvimento da criança, sua capacidade atual em solucionar problemas e o grau em desenvolver seu potencial, por meio da orientação de adultos para resolução destes, 
ou seja, todo o aprendizado leva ao desenvolvimento (Oliveira, 1997, p. 23). Ainda segundo Vygotsky (1998), para entender o desenvolvimento da criança é necessário levar em consideração as necessidades, as motivações e os incentivos mais eficazes para coloca-las em ação, daí a importância da participação efetiva dos pais nas atividades escolares dos filhos. Compreendeu-se neste estudo, que para os pais acompanharem as atividades escolares dos filhos, foi necessário sistematizar o aprendizado e aprofundar os conhecimentos, por estes pais, além de ser um momento de interação e troca, não alterando de forma significativa a dinâmica e a rotina dos pais.

\section{Considerações Finais}

O presente trabalho teve por objetivo investigar as relações entre os responsáveis e os filhos que estão em confinamento em casa, realizando tarefas do trabalho e escolares em conjunto, muitas vezes no mesmo ambiente.

Em síntese, pode-se destacar que o desempenho da criança depende do acompanhamento, do apoio, da credibilidade e do compromisso dos seus responsáveis legais, para que possa desenvolver-se de forma plena, tanto em termos cognitivos como emocionais. As crianças têm se esforçado para realizar as aulas remotas com seus pais e acompanhar os estudos, entretanto, em alguns casos crianças demonstram um certo desinteresse, talvez pelo fato do computador ser um 'meio frio' para interação humana, gerando certo estresse por parte dos pais, que por não entenderem o que se passa com o filho tendem a optar por ações punitivas. Neste contexto, temos que considerar a importância do papel da família, para o desenvolvimento social, cognitivo e na formação da subjetividade, influenciando e repassando as formas de entendimento e compreensão do mundo para a criança, repercutindo na formação do seu mundo interno, no seu modo de pensar e agir.

Com base no objetivo deste estudo, consideramos que obtivemos resultados positivos quanto a investigação das relações entre os responsáveis e os filhos que estão em confinamento em casa, realizando tarefas do trabalho e escolares em conjunto, muitas vezes no mesmo ambiente. No cenário atual de distanciamento social percebe-se que muitos pais precisam via de regra acordar muito cedo para dar conta de todas as atividades propostas para o dia. Acordam mais cedo, preparam o café, realizam as atividades do trabalho doméstico: lavar a louça, limpar a casa, preparo das refeições, dentre outras. Aliado a isso, existe um esforço dos pais para conseguir viabilizar as aulas de seus filhos no modelo remoto, isso porque esses pais também estão trabalhando em home-office em suas casas (muitos desses 
pais inclusive mudaram o horário de trabalho, em decorrência da pandemia) e muitos deles também cursam ensino superior e/ou médio/técnico em horários específicos do dia.

Nota-se ainda que como o uso dos computadores e recursos é compartilhado, as famílias precisam se desdobrar: por exemplo, enquanto um está fazendo aulas remotas e desenvolvimento de atividades que sejam necessárias pelo computador/notebook, outro está assistindo uma aula / palestra que não necessite de muita interação, pelo smartphone; enquanto outro membro da família realiza atividades domésticas. Ainda assim, depois ocorre um 'rodízio' dos equipamentos / recursos. Pretende-se futuramente desenvolver um estudo enfocando os aspectos emocionais presentes na relação entre pais e filhos em tempos de pandemia.

\section{Referências}

Almeida, E. B. (2014). A relação entre pais e escola: a influência da família no desempenho escolar do aluno. Campinas, SP, [s.n.], Trabalho de conclusão de curso (graduação) Universidade Estadual de Campinas, Faculdade de Educação. Recuperado de file://C:/Users/Celia\%20Regina/Downloads/AlmeidaEmanoelleBon\%C3\%A1ciode_TCC\%2 $0(2) \cdot p d f$

Aquino Filho, G. F., Amaral, L. H., \& Schimiguel, J. (2015). Utilização de blog para a construção de um ambiente colaborativo. Atlante: Cuadernos de Educación y Desarrolo. (10)

Belo, F., \& Scodeler, K. (2013). A importância do brincar em Winnicott e Schiller. Tempo psicanal. Rio de Janeiro, 45(1), 91-101, Recuperado de. <http://pepsic.bvsalud.org/scielo .php?script=sci_arttext\&pid=S0101-48382013000100007\&lng=pt\&nrm=iso .

CrespaldI. E. M. F.(2017). A importância da família na escola para a construção do desenvolvimento do aluno. Formação de Professores: Contextos, Sentidos e Práticas. SIPD/Cátedra/UNESCO, UNESPAR, Campo Mourão/PR. Recuperado de. https://educere.bruc.com.br/arquivo/pdf2017/25972_13983.pdf 
Dessen, M. A., \& Polonia, A. C. (2007) A Família e a Escola como contextos de desenvolvimento humano. Scielo 37 Brasil, Universidade de Brasília, Distrito Federal, Brasil, 21-32. Recuperado de https://www.scielo.br/pdf/paideia/v17n36/v17n36a03.pdf.

Ferhamann, P. G., Keith, T. Z, Reimers, T. M. (1987). Home influence on school learning: Direct and indirect effects of parental involvement on high school grades. Journal of Educational Research, 80, 330-337. Recuperado de https://www.tandfonline .com/doi/abs/10.1080/00220671.1987.10885778

Freitas, H., Oliveira, M., Saccol, A. Z., Moscarola, J. (2000). O Método de Pesquisa Survey. Revista de Administração, São Paulo, 35(3),105-112, julho/setembro de 2000.

Grolnick, W., \& Slowiaczek, M. L. (1994). Parent's involvement in children's schooling: A multidimensional conceptualization and motivational model. Child Development, 65, 37-252. Recuperado de https://www.jstor.org/stable/1131378?seq=1

Hodges, C., Moore, S., Lockee, B., TRust, T., \& Bond, A. (2020). The Difference Between Emergency Remote Teaching and Online Learning. Educause Review [on-line]. Recuperado de https://er.educause.edu/articles/2020/3/the-difference-between-emergency-remoteteaching-and-online-learning.

Marturano, E. M. (1999). Recursos no ambiente familiar e dificuldades de aprendizagem na escola. Psicologia: Teoria e Pesquisa, 15, 135-142. Recuperado de <http://www.scielo.br/scielo.php?script=sci_arttext\&pid=S0102-37721999000200006 $\& \operatorname{lng}=$ en $\&$ nrm $=$ iso $>$.

Nogueira, M. A. (2006). Família e Escola na contemporaneidade: os meandros de uma relação. Educação e Realidade, 155-170. Recuperado de https://www.redalyc.org/pdf/3172/317227044010.pdf.

Oliveira, M. K. (1997). Vygotsky Aprendizado e desenvolvimento um processo sócio histórico. São Paulo: Scipione. 
Papalia, D. E., \& Feldman, R.D. (2013). Desenvolvimento humano. (12a ed.), Porto Alegre: Artmed.

Roque, A. A., Ioris, E. G., Signorati, A., Moreira, F. L., Tessaro, D., \& Kovalski, M. L. (2020). Eating habits of elementary school children - A field survey. Research, Society and Development, 9(5). Recuperado de https://rsd.unifei.edu.br/index.php/rsd/article/ view/3240/2495. Último acesso: 23/07/2020.

Schmidt, B., et al. (2020). Saúde mental e intervenções psicológicas diante da pandemia do novo coronavírus (COVID-19). Estud. Psicol. (Campinas), Campinas, 37, e200063. Recuperado de <http://www.scielo.br/scielo.php?script=sci_arttext\&pid=S0103166X2020000100501\&lng=en\&nrm=iso>. https://doi.org/10.1590/1982$0275202037 \mathrm{e} 200063$.

Soares, M. R. Z., Souza, S. R., \& Marinho, M. L.(2004). Envolvimento dos pais: incentivo à habilidade de estudo em crianças. Estudos de Psicologia, Campinas, 21(3), 253-260. Recuperado de https://www.researchgate.net/publication/250050978_envolvimento_dos_ pais_incentivo_a_habilidade_de_estudo_em_criancas

Souza, J. L. C., Ferreira, V. M. B., \& Moraes, M. (2019). Survey of aquatic insects on a stretch of tijuca river, Floresta da Tijuca - Rio de Janeiro, Brazil. Research, Society and Development (RSD), 9(1). Recuperado de https://rsd.unifei.edu.br/index.php/rsd/article /view/1847.

Teixeira, D., \& Finardi, K. R. (2013). TICs no ensino presencial: evidências de um curso de formação continuada na Universidade Federal do Espírito Santo. Contextos Linguísticos. [Online]. Recuperado de https://www.researchgate.net/profile/Kyria_Finardi/publication/ 318635299_TICs_no_Ensino_Presencial_Evidencias_de_um_Curso_de_Formacao_Continua da_na_Universidade_Federal_do_Espirito_Santo/links/5972ec3d0f7e9b40169457ad/TICs-noEnsino-Presencial-Evidencias-de-um-Curso-de-Formacao-Continuada-na-UniversidadeFederal-do-Espirito-Santo.pdf.

Vilaça, F. A., Brito, A. S., Schimiguel, J., Val, M. L., \& Santos, M. E. K. L. (2015). Importância da Plataforma Dokeos para o Ensino de Histologia. Espacios. 36(23) 
Vygotsky, L. S. Pensamento e linguagem. (2a ed.), São Paulo: Martins Fontes, 1998.

Winnicott, D. W. (1958/2000). Da pediatria à psicanálise: obras escolhidas por D. W. Winnicott; com uma introdução de Masud M. Khan. Rio de Janeiro: Imago.

\section{Porcentagem de contribuição de cada autor no manuscrito}

Célia Regina da Silva Rocha, - 33,3\%

Juliano Schimiguel, - 33.3\%

Graziela Viana Pires - 33,3\% 